\title{
Conectores de oposição: reflexões e propostas para o ensino
}

Maria Aparecida Lino Pauliukonis ${ }^{a}$

\begin{abstract}
Resumo
Estudo reflexivo e produtivo dos conectores de oposição em português, com o objetivo de sensibilizar os alunos interpretantes para a importância de seu papel semântico-argumentativo e pragmático em diferentes gêneros textuais. Tal enfoque possibilita oferecer uma visão discursiva dos conectores em lingua portuguesa, o que pode contribuir para uma melhora significativa do processo de leitura e de produção textual.
\end{abstract}

Palavras-chave: Conexão. Interpretação. Produção textual. 


\section{Introdução}

Este artigo tem por objetivo apresentar propostas de operacionalização dos ensinamentos da Linguística do Texto, ou seja, aplicar seus conceitos à produção e à interpretação de textos, realizados em determinadas situações sócio-comunicativas. Por meio de uma análise reflexiva sobre a natureza e a função discursiva dos elementos constituintes de um enunciado, apresentam-se algumas discussões teóricas e propostas pedagógicas sobre o uso de conectores de oposição em níveis frasais e textuais, que possibilitarão aos alunos aprimorar sua capacidade de compreensão e de produção textual.

Propõe-se uma revisão no ensino de gramática da língua, tradicionalmente enfocada sob uma visão metalinguística como um fim em si mesma, em favor de uma reflexão sobre o funcionamento e valor semântico dos elementos linguísticos. É o que se objetiva aqui, com referência a um estudo mais produtivo dos conectores, cujo papel discursivo na estruturação de textos é primordial para o entendimento dos sentidos. O termo - conectores - engloba tanto os conectivos da Gramática tradicional, como as locuções conjuntivas, adverbiais e prepositivas. Neste espaço, serão tratados somente os conectores do grupo da oposição, que se referem aos conectivos coordenativos, subordinativos e locuções, vistos em sua função discursivo-argumentativa.

Segundo orientações dos Parâmetros Curriculares Nacionais (PCNs), um dos objetivos principais do ensino de língua materna é desenvolver a competência comunicativa do aluno e, em decorrência disso, deve-se estimular um ensino reflexivo sobre os elementos gramaticais e discursivos, para aquisição de novas habilidades linguísticas, na composição e na interpretação de textos. Dentre as prioridades, estão várias competências /saberes da língua permeados pelo desenvolvimento do letramento crítico.

O que significa dar importância a um ensino produtivo dos elementos constitutivos do texto? Para se responder a essa questão, é preciso considerar algumas concepções de linguagem, que se fundamentam em alguns princípios bastante discutidos pelos teóricos do texto: 
- Linguagem é um instrumento e uma forma de interação social entre um emissor e um receptor; o ensino deve priorizar o uso contextual mais amplo desse instrumental;

- Todo texto congrega um conjunto de marcas, de pistas linguístico-discursivas que funcionam como instruções para o estabelecimento de sentidos previsíveis em cada gênero textual visto como um ato de interação;

- A compreensão dos textos envolve processos sócio-cognitivos que permitem relacionar sistemas variados de conhecimento, a saber: o linguístico, o enciclopédico e o interacional.

Pode-se afirmar, portanto, que toda sequência linguística pode ser analisada como parte integrante de um processo interativo mais amplo e o que lhe dá sua característica fundamental, - a textualidade -, é o fato de ser a frase uma parte integrante de uma unidade maior - o texto - a que pertence.

Procurando atingir esses propósitos, este artigo apresenta um estudo reflexivo sobre o emprego dos conectores de oposição em Português, procurando sensibilizar o aprendiz para a importância de seu papel sintático e semântico-argumentativo na composição textual.

Assim, por meio da análise dos mecanismos que ligam os enunciados uns aos outros, estabelecem-se as relações opositivas, num processo denominado "argumentação refutativa". De acordo com os conectores usados, obter-se-ão variados efeitos de sentido, segundo o contexto e a situação em que se realizam as sequências textuais.

\section{Estudo reflexivo de conectores}

Tradicionalmente, o ensino da estruturação sintática do período composto em português tem se restringido ao âmbito da classificação de orações e do reconhecimento do tipo de conectivos que as relacionam. Paralelamente fornece-se aos alunos uma lista de conjunções (locuções) coordenativas e subordinativas, divididas em subtipos: (aditivas, adversativas, conclusivas..., temporais, causais, condicionais, concessivas, finais... etc.). Muitas vezes não lhes é explicitado que esses nomes e subtipos identificam relações sintático-semânticas que se estabelecem entre as proposições e que podem ser do tipo 
lógico e/ou discursivo; muitas vezes, os alunos não as reconhecem ou não usam produtivamente na redação de seus textos.

Parece mais plausível, dentre os objetivos aqui traçados, que se discutam as relações entre as proposições conectadas pelos diferentes tipos de elementos concessivos ou restritivos, bem como seu potencial enunciativo-argumentativo nos textos. Para tanto, apresentam-se reflexões sobre os conectores que introduzem ideia de oposição e seu papel no processo da argumentação em textos.

\section{Conectores do grupo de oposição}

Com a noção base de contraste, esse grupo indica restrição a uma proposição dada, o que ocorre tanto na estrutura da coordenação, pela construção adversativa, como na da subordinação, por meio da construção concessiva. Assim nos dois enunciados: Ela é bonita, mas é antipática; Embora ela seja bonita, é antipática mantém-se o argumento negativo mais forte ela é antipática, que se opõe e restringe a qualidade positiva de beleza expressa na outra parte da proposição.

Não há dúvidas sobre a relação estreita que existe entre as duas estruturas - a coordenada e a outra subordinada - 0 que permite a paráfrase de uma pela outra, mas existe, segundo Castilho (2010, p. 377) “(...) um caso mal resolvido entre as coordenadas adversativas e as subordinadas concessivas", pois entre elas acontecem fatos gramaticais e fatos discursivos dignos de uma análise mais profícua. A principal diferença, segundo o autor, está no fato de que nas adversativas adia-se a negação de expectativas e na concessiva, antecipa-se a negação, alternando-se o "eixo argumentativo" do enunciado e, consequentemente, seus efeitos de sentido.

Gramaticalmente, dentre os principais conectivos que introduzem o raciocínio de oposição, destacam-se os coordenativos adversativos mas, porém, todavia, contudo, no entanto, com o verbo no modo indicativo, e os conectivos subordinativos concessivos embora, ainda que, posto que, se bem que, mesmo que, posto que apesar de... com o verbo no modo subjuntivo.

Há ainda a observar os conectivos ditos contrastivos enquanto que, ao passo que..., com o emprego do verbo também no indicativo, introduzindo construções, a meio caminho entre a coordenação e a subordinação, mas com mobilidade maior da 
posição da adverbial, como se pode ver em Gosto de português, ao passo que ela prefere Matemática, ou Ao passo que ela prefere matemática, eu gosto de português.

Quanto ao conector se bem que, ele é usado normalmente com o verbo no subjuntivo: Ele me pediu auxílio, sebem que nem precisasse tanto. Pode-se usar o indicativo, quando a oração vier posposta à oração base: Ele estudou com afinco, se bem que a prova estava muito fácil.

Além dos conectivos citados, há várias expressões que assumem valor concessivo "É claro que; é óbvio que; de fato; sob esse ponto de vista; evidentemente que ...etc, o que levou à opção pela denominação conectores que engloba todos os marcadores de oposição, como se pode ver no exemplo: De fato ele é seu amigo, receio, porém, que não o ajudará dessa vez, pois está muito mal de finanças.

Entre as variáveis para se obter um matiz semântico de cunho enfático, no uso das proposições concessivas, podem ser observadas ainda as seguintes construções:

- concessiva intensiva: Por mais que o convidem, ele não virá à recepção;

- correlação concessiva: Quanto mais ele se oferece, menos ela o aceita como pretendente.

\section{Valores argumentativos na concessão}

Imagine-se a seguinte situação de sala de aula, em que um professor rigoroso diz a um aluno:

- Embora seu trabalho esteja muito bom, não vou lhe dar conceito excelente, para não ficar convencido. (ou: - Seu trabalho está muito bom, mas não vou the dar conceito excelente para não ficar convencido.)

Segundo o princípio de que o uso de todo enunciado é parte de um "texto em situação", ou seja, faz parte de uma interação discursiva, dado o seu caráter dialógico e polifônico, o emprego do raciocínio concessivo expressa sempre uma contestação a um discurso argumentativo de outrem, cujo valor em parte é admitido pelo locutor, mas ao qual vai contrapor um argumento contrário e mais forte.

No exemplo dado, contesta-se o valor argumentativo expresso pela oração concessiva - a qualidade do trabalho- mas sem negar seu valor de "verdade" ou seu peso na argumentação. 
Ao reconhecer o valor do trabalho, o locutor qualifica esse fato como um argumento favorável para a conclusão X - logo, deve receber conceito excelente. Por outro lado, o locutor distancia-se desse raciocínio, propondo uma outra conclusão $Y$, que deve predominar na argumentação, derivada da proposição principal: não vou the dar conceito excelente, para não ficar convencido.

Há como que um acordo implícito: o enunciador leva em consideração o argumento do outro, reconhece seu "peso" argumentativo, mas apresenta obstáculos à conclusão pretendida e propõe um argumento contrário e mais forte, como uma forma de refutação ao raciocínio do outro. É como se "fingisse" lhe dar razão, ou reconhecer algum valor no argumento, para em seguida, lhe tirar o "tapete", comparação feita por um colega, em debate sobre concessão.

O estudo de conectores como operadores argumentativos ou como marcas do processo de "argumentação na língua" foi proposto pela Semântica Argumentativa de Oswald Ducrot \& J.C.Anscombre (1987) e também revisto e ampliado com aplicação a diferentes contextos por diversos pesquisadores brasileiros, dentre os quaiscitam-se: Guimarães (1987), Koch (2004), Oliveira \&Monnerat (2005) e Gouvêa (2006).

Constitui o raciocínio concessivo uma importante técnica argumentativa, pois, ao incorporar ao seu argumento pontos de vista contrários, o locutor mostra-se uma pessoa de espírito aberto, ou que tem um comportamento liberal, e esse fato é bastante positivo para sua própria argumentação; mesmo que ele não considere o peso desse argumento em sua avaliação final, pois instaura seu ponto de vista na cláusula principal. Portanto, há no jogo da concessão, uma trégua ilusória proposta pelo locutor que relega o raciocínio do outro a uma posição secundária, superando-o com seu argumento mais forte, como expresso no exemplo dado: " (mas) não vou the dar conceito excelente para não ficar convencido".

A construção com oração subordinativa de valor concessivo constitui, assim, uma forma típica de argumentar, como descreve o processo o linguista Celso Cunha (CUNHA;CINTRA, 1985), em que se toma como um dos pontos o que é dito na subordinada, ou em que se admite um fato contrário à ação principal, mas incapaz de impedi-lo.

O exemplo seguinte vem ilustrar também esse raciocínio: Embora chovesse muito, foi à praia, pois era fanático por banho de 
mar. A chuva poderia impedir a ida à praia, o que não ocorreu, e a justificativa para o ato contrário à conclusão do primeiro segmento é o seu fanatismo pelo mar; ou este outro exemplo construído com estrutura adversativa: Sou seu amigo, mas não posso ajudá-lo neste momento, fato em que a amizade não se mostra como condição suficiente para o auxílio.

Nesse sentido, a noção de conceder remete à ideia de defender uma certa tese, por oposição a outras teses, mas de uma forma peculiar. É uma forma de responder ao discurso de um outro, ouvir e considerar a sua voz, contestando-lhe o valor argumentativo, sem anular o "valor de verdade" dessa enunciação. Por isso a concessão situa-se a meio caminho entre a aprovação e a contestação. Nesse jogo, o locutor faz ouvir a voz do outro argumentador, mas se distancia dele, levando em consideração outro ponto de vista.

Esse ato de integrar o outro em seu discurso visa a enfraquecê-lo, como a mostrar uma estratégia de trégua ilusória, mas que se apresenta como uma etapa do combate, fase essa importante no processo argumentativo. A concessão é indissociável da polêmica que cria uma situação semelhante a um simulacro de guerra, mas de uma guerra discursiva com forte valor argumentativo que funciona em qualquer situação.

Dessa forma, consiste a operação concessiva em uma estratégia complexa e muito eficaz na construção de textos argumentativos. Veja-se o fragmento de um texto noticioso, a seguir, "Ainda que a polícia tenha conseguido prender os ladrões, as joias não foram recuperadas, infelizmente, comentou o casal assalta$d o^{\prime \prime}$, em que a prisão foi considerada um fator relevante a favor da ação policial, mas o objetivo principal - a recuperação das joias - não ocorreu, o que encaminha o leitor para a conclusão negativa; essa conclusão é reforçada pelo uso do advérbio de modalização subjetiva "infelizmente", que marca a decepção das vítimas perante o fato ocorrido.

\section{Operadores e jogo argumentativo}

Os conectivos adversativos e concessivos, introdutores das noções de restrição e concessão, em orações coordenadas e subordinadas, respectivamente, além de alterarem o "eixo argumentativo", apresentam várias sutilezas semânticas. A seleção de um e não de outro permite ao locutor realizar ma- 
nobras discursivas peculiares que resultam diferentes efeitos de sentido, que são úteis ao aluno no processo das argumentações e interpretações de texto.

A seguir, observam-se exemplos de como essas nuances semânticas ocorrem nos diferentes empregos dos conectivos mas, porém, no entanto, todavia, apesar de, por mais que, mesmo que, ainda que, embora e outros.

Mas: é o conectivo adversativo mais usado em português; introduz o argumento mais forte, em oposição à ideia existente na oração de menor peso argumentativo (secundária); nesse caso, é pertinente invocar sua etimologia latina: magis(mais), que vem reforçar sua participação no comparativo de superioridade e também na introdução da ideia de preferência, como se vê no enunciado dialógico, a seguir, ouvido alhures:

- Mãe, perdi meus brincos. A senhora sabe onde estão?

- Não! Já varri a casa toda, mas sua irmã foi ao cinema.

Pela fala da mãe, pode-se inferir que a expressão já varri a casa toda é usada para explicitar que o argumento de que os brincos teriam caído no chão da casa não se sustentaria, pois não foram ali encontrados. A sequência "mas sua irmã foi ao cinema" apresenta o argumento mais forte que pode indicar que a mãe está insinuando que a irmã talvez os tenha levado ou que só ela saiba onde estariam. Observe-se que a situação apresentada entre mãe e filha completa o quadro enunciativo, segundo o qual o sentido do texto é sempre co-construído numa relação dialógica.

Considerado o conector argumentativo por "excelência", o mas foi estudado exaustivamente por Oswald Ducrot e por J.C. Anscombre (1981, p.255), que propõem sua caracterização como mas $P A$, correspondente ao espanhol pero e ao alemão aber, ou como o conector que instaura uma operação argumentativa polêmica, em que o locutor defende seus argumentos com base numa superioridade argumentativa, que já está indicada no próprio uso do conector, como se pode observar no título da conhecida obra de Nélson Rodrigues: "Bonitinha, mas ordinária".

Porém: apresenta uma natureza restritiva menos forte, como se o locutor quisesse mostrar que algo é omitido e que a presença do conectivo permite uma correção do rumo do raciocínio conduzindo-o para uma outra conclusão, como 
se houvesse um reajuste de foco no argumento principal.Tal interpretação encontra fundamento também na etimologia do termo, ligado à forma do latim "per inde", que significa no lugar de.

Em um diálogo entre pai e mãe, ouve-se do pai, sobre o comportamento da filha adolescente, a observação restritiva ao raciocínio da mãe:

-Você acha normal que elasaia sozinha à noite e volte tarde. Está certo que ela não é mais uma criança, porém dizer que já é adulta eu acho um absurdo.

Observe-se que o conector introduz uma refutação dissociativa, menos forte do que permitiria o uso de mas, já que parece colocar algo no lugar de um raciocínio feito, com vistas à substituição desse raciocínio por outro, de peso mais relevante.

Quando porém está seguido de um advérbio modalizador como - na verdade - instrui melhor o leitor a não se deixar impressionar pela ideia secundária, evitando-se de vez que se tome o fato secundário pelo fato principal, com o efeito de maior ênfase pelo emprego do conectivo seguido do modalizador.

Veja-se o exemplo: “As pessoas se dizem solidárias, porém o que falta, na verdade, é companheirismo e ajuda mútua" (blog. giselebundchen.com.br)

No entanto: denota um certo estranhamento diante do que é comunicado e que pode ser considerado até um absurdo pelo enunciador. Melhor dizendo: de fato, coexistem dois argumentos contrários e fortes, em que se enfatiza o que é enunciado por "no entanto". Pelo exemplo contextualizado, fica mais fácil entender o raciocínio: alguém, fazendo uma análise de um comportamento de uma amiga, por ele considerado bastante estranho, afirma: “ - A dedução óbvia é a de que ela não deveria ter ido lá, à noite e sozinha, no entanto ela foi, acho que está louca, não?"

Raciocínio semelhante pode ser observado no célebre e conhecido anúncio do início do século passado, publicado em bondes, sobre as maravilhas do xarope Rhum Creosotado 
para a cura de bronquite; o uso do conector denota esse grau de estranhamento diante do que vai ser enunciado:

"Veja o ilustre passageiro,

o belo tipo faceiro

que o senhor tem a seu lado.

No entanto, acredite...

quase morreu de bronquite

salvou-o o Rhum Creosotado".

O poder do medicamento é realçado pelo fato de o atual "belo tipo faceiro" quase ter morrido de bronquite, sendo salvo pelo milagroso Rhum Creosotado.

Todavia, entretanto e contudo: em função da contiguidade sintático-semântica com as locuções adverbiais de onde se originam e, mantendo o valor de um ato de fala com ideia de ênfase, passaram esses conectores a adquirir também valor de oposição em contato com outras cláusulas de valor concessivo, mas mantiveram ainda a mobilidade sintática que lhes permite ocupar diversas posições dentro do enunciado, ao contrário do conector mas, de posição mais fixa; às vezes, podem até se articular com ele, como se pode ver no exemplo: A polícia prendeu os assaltantes, mas as joias, no entanto, não foram recuperadas; mas as joias não foram, contudo, recuperadas.

Essa aludida mobilidade na colocação desses conectores no período pode ser observada em:

Ele veio, mas não quer, todavia, (contudo, entretanto) que ninguém saiba.

Ele veio, (contudo, todavia, entretanto) não quer que ninguém saiba.

Apesar de (que): A seguir, observe-se o comentário de alguém sobre a notícia de um grave acidente noticiado em um jornal televisivo: "Apesar de ter havido tantos mortos na tragédia, ele escapou ileso. Foi um milagre!"

O conteúdo do primeiro segmento exprime a não satisfação de uma condição mínima para que se verifique a avaliação esperada ou a realização daquilo que se afirma na oração principal. O acidente foi muito grave, logo todos deveriam ter morrido, raciocínio fruto de uma conclusão lógica e de 
argumentos válidos (que se apresentam com um certo peso, daí o uso do conector "apesar de"); a realização do segundo membro confirma a conclusão principal: a possibilidade de ter havido um milagre como argumento já que ele escapou ileso.

Por mais que e Até mesmo: Esses termos marcam uma gradação e situam o argumento no topo de uma escala argumentativa que direcionaria o ouvinte/leitor para uma conclusão esperada, dado o peso do argumento encarecido pelos advérbios de intensidade; mas o que se tem mesmo é a predominância da argumentação principal. Vamos observar o exemplo a seguir:

- Por mais que ele implorasse, ela não o perdoou, pois foi grave sua culpa". Até mesmo ele implorando seu perdão, ela não o perdoou.

Ainda que e mesmo que: De modo semelhante, também no emprego desses conectores, observa-se a introdução de certos argumentos possíveis e com bastante peso argumentativo, graças aos operadores "mesmo" e "ainda", que estabelecem encarecimento de uma ideia a ser considerada: "Ainda que ela peça de joelhos" ou "Mesmo que se derreta em lágrimas", ideias essas que vêm confrontadas com o argumento principal, que é apresentado como o mais forte "ele não a perdoará.", argumento principal que poderia estar reforçado por "mas" ou por outro conector adversativo, que marca sua predominância: "mas, mesmo assim, ele não a perdoará".

Embora: O mais usual dos conectivos de concessão, embora serve para transmitir o sentido de uma trégua ilusória. Sua origem prende-se à locução adverbial "em boa hora", por possuir aspecto volitivo de bons desejos, cujo emprego era expresso no modo subjuntivo; mantinha o termo antônimo "em má hora", para expressar os maus augúrios, de acordo com a posição dos astros, no momento de saída para uma viagem. Ambos eram empregados com valor adverbial de tempo.

Como a ideia era transmitir bons votos de viagem a quem ia seguir caminho, era comumente usado após o verbo $i r$, como se vê em: "Vamos em boa hora nosso caminho" (CASTILHO, 2010, p.378). O uso com o que de valor volitivo permitiu que se dissesse: Embora que não tenha razão, ainda assim insiste em ficar, mantendo-se, assim, o uso do modo subjuntivo. 
Com o processo de gramaticalização, esvaziou-se o caráter volitivo da expressão que passou a ter um valor dêitico, que marca uma ideia de separação de algum lugar. Foram embora daqui. Vá embora já daqui! Sem o elemento que, o conector embora assumiu o papel de uma conjunção subordinativa concessiva, mantendo ainda o valor de expectativa, que é o seu conteúdo semântico mais usual; o emprego desse conector na construção concessiva é bastante frequente em português, como atestam os vários usos em diferentes gêneros de textos escritos e na fala diária: "Embora seja meu amigo, não posso ajudá-lo, infelizmente."

Com valor concessivo e emprego do verbo no subjuntivo, o conector embora, com nuances diferenciadas, a depender de sua posição no enunciado, marca uma ideia secundária mas cujo valor semântico o define como uma excelente estratégia argumentativa. Isso talvez seja resquício do conteúdo positivo de sua expressão de origem "em boa hora", relacionada ao desígnio da concordância dos astros em favor de uma viagem que se inicia; essa positividade sinaliza um argumento secundário importante, que deve ser considerado no jogo argumentativo, mesmo que a orientação argumentativa do enunciado seja marcada sempre pela ideia expressa na cláusula principal.

\section{Considerações finais}

Como se pôde observar, há uma série de complexidades que envolvem o ato de interpretar os sentidos expressos pelos conectores de oposição. Todos os fatores apontados sugerem que cada texto se apresenta como uma rede de relações, que envolve a escolha vocabular, a estrutura e organização das frases e a representação linguístico-discursiva de uma intenção argumentativa dos enunciadores, que instauram verdadeiros atos de fala, apoiados em construções sintático-semânticas; esse jogo é assim explicitado nos variados usos dos conectores com ideia de oposição/concessão, como se analisou aqui.

Sempre é bom repetir: texto é tecido, trama, rede de relações entre enunciados, entre autor e leitor, situação e contexto diversificados, por isso o ato de ler envolve apreensão do modo como se organizam essas relações na transformação de um conteúdo em linguagem. Ler sem reconhecer ou recriar o 
processo de construção do texto é praticar uma pseudoleitura, uma mera descodificação de estruturas de frases isoladas ou coladas umas às outras.

Ao efetivar uma leitura consciente, o leitor realiza um ato de compreender como se constrói uma visão do mundo, representada por meio das construções linguísticas. Por isso, a leitura crítica e eficaz pressupõe o enriquecimento do leitor pelas múltiplas possibilidades de significação que se abrem diante de um texto, o que é feito pelo conhecimento primeiro da função dos elementos linguísticos que o compõem; e, dentre eles, são relevantes os elementos que funcionam como operadores argumentativos, tema destas considerações.

Nesse sentido, todo ensino de leitura ou de escrita com base reflexiva assume uma dimensão social bem maior do que o mero ato de ensinar a decifração de sintagmas e de frases e se instaura como um veículo de formação da cidadania, base do processo de letramento, em sentido amplo, como hoje se exige de uma educação.

Entende-se que, desde a divulgação dos PCNs (1998), os contextos sociais e educacionais mudaram e hoje, cada vez mais, é preciso estimular a aprendizagem de vários aspectos multimodais dos textos, sendo que a ênfase apenas na habilidade da descodificação do signo verbal parece não mais satisfazer as necessidades dos aprendizes de hoje na era digital. No entanto, não se pode menosprezar a compreensão dos jogos do sentido no uso dos signos linguísticos em contextos sócio-interacionais.

As noções apresentadas propiciam uma reflexão sobre a necessidade de aprimoramento da capacidade de utilizar a língua em várias situações interativas específicas. Para desenvolver a competência comunicativa dos alunos, que é um dos objetivos do ensino de gramática reflexiva, é necessária a aquisição de novas habilidades, que um enfoque discursivo do emprego dos conectores, por exemplo, pode ajudar a implementar. Ao lado desse ensino reflexivo e produtivo, o descritivo e o normativo também têm seu lugar, evidentemente, mas devem ser redimensionados, em comparação com as práticas que se têm observado tradicionalmente nas escolas, sobretudo aquelas relacionadas ao ensino de conectores e de outros elementos linguístico-discursivos na construção dos sentidos do texto. 


\section{REFERÊNCIAS}

CASTILHO, Ataliba T.de. Nova Gramática do português brasileiro, São Paulo: Contexto, 2010.

CUNHA, Celso \& LINDLEY CINTRA. Gramática do português contemporâneo. Rio de Janeiro: Nova Fronteira, 2007.

DUCROT, Oswald . O dizer e o dito. Campinas: Pontes, 1987.

\& ANSCOMBRE, J.C. Provar e dizer, leis lógicas e leis argumentativas. São Paulo: Global, 1981.

GOUVÊA. Lúcia Helena M. Operadores argumentativos: uma ponte entre a língua e o discurso. In: PAULIUKONIS, M.A.L. \& Werneck, Leonor. (Orgs). Estratégias de leitura: texto e ensino. Rio de Janeiro: Lucerna, 2006,p.104-116.

GUIMARÃES, Eduardo. Texto e argumentação:um estudo de conjunções do português. São Paulo: Pontes, 1987.

$\mathrm{KOCH}$, Ingedore V. Argumentação e linguagem. 9.ed. São Paulo: Cortez, 2004.

OLIVEIRA, Helênio F.de \& MONNERAT, Rosane S. M. O emprego de algumas conjunções no texto .In: PAULIUKONIS, Maria A.L.\& GAVAZZI, Sigrid.(Orgs). Da lingua ao discurso:reflexões para o ensino. Rio de Janeiro: Lucerna, $2^{\mathrm{a}}$.ed, 2007, p.90-102. PAULIUKONIS, M.A.L. Os conectores de causalidade. In RevistaLetra, UFRJ, v. 7, n.1, jan/jun 2005, p.35-42.

blog.giselebundchen.com.br consultado em 14 de novembro de 2013. 


\section{Abstract}

Connectives of opposition: reflections and proposals for teaching

A reflexive and productive study on connectors of opposition in Portuguese, aiming at making students pay attention its semantic-argumentative and pragmatic roles in different textual genres. Such approach focus enables a discursive view about connectors in Portuguese, something that can also contribute to a significant improvement in reading and textual production processes.

Keywords: Cohesion. Interpretation. Textual production. 